\title{
Combined 3D Surveying and Raman Spectroscopy Techniques on Artifacts Preserved at Archaeological Museum of Lipari
}

\author{
Dario Giuffrida $^{1}{ }^{\circledR}$, Viviana Mollica Nardo ${ }^{1, *}$, Fausta Giacobello ${ }^{1}$, Oreste Adinolfi ${ }^{2}$, \\ Maria Amalia Mastelloni ${ }^{3}$, Giovanna Toscano ${ }^{1}$ and Rosina Celeste Ponterio ${ }^{1}$ D \\ 1 IPCF-CNR, Viale F. Stagno d'Alcontres 37, 98158 Messina, Italy \\ 2 FARO Europe GmbH \& Co. KG, Am Wiesenbusch 1, 45966 Glabeck, Germany \\ 3 Former Director of Polo, Parco Archeologico e Museo “L. Bernabò Brea”, Via Castello 2, 98050 Lipari, Italy \\ * Correspondence: mollica@ipcf.cnr.it
}

Received: 18 June 2019; Accepted: 17 July 2019; Published: 18 July 2019

check for updates

\begin{abstract}
Over the last years, the documentation of Heritage has been increasingly enriched with new forms of data representation and contents deriving from technological applications on artifacts and the progress of computer graphics: if, on the one hand, 3D survey has become an effective tool supplementing and supporting traditional study activities, as it can generate accurate and high-resolution digital models (available especially when physical access to materials is not possible, but also for enhancement or to formulate hypothetic reconstruction), on the other, archaeometry investigations can provide all that information (about composition, firing temperature of clay, etc.) that autopsy, comparison, formal, contextual, or bibliographic analysis cannot do on their own. This paper aims to show the potentialities of combined use of these non-destructive and non-contact approaches on the archaeological artifacts preserved at the Regional Museum of Lipari "L. Bernabò Brea" for the analysis, diagnostic, fruition, and forthcoming restoration purposes. Different methodologies, such as laser-based surveying, sfm digital photogrammetry, and Raman spectroscopy have been, respectively, adopted and combined to get reconstruction and characterize several clay masks and two figured calyx-kraters. The latter technique, in particular, has proved to be useful in compositional analysis of dyes and pigments contained in the clay.
\end{abstract}

Keywords: Lipari Museum; Clay masks; 3D surveying; Raman spectroscopy; enhancement; archaeometry

\section{Introduction}

The Regional Archaeological Museum of Lipari "L. Bernabò Brea" is located upon the rock of the "Castle", an imposing dome of volcanic formation with characteristics of the natural fortress. The classic section of the itinerary exhibits a large collection of clay masks and statuettes, found during archaeological excavations, that are one of the most distinctive material evidences of Greek civilization of Lipára [1]: most of them come from funerary equipment of the tombs found at "Contrada Diana" or from votive "pits" or "dumps" located in sanctuary and the areas of necropolis, few others come from domestic and worship contexts placed in urban and peri-urban areas [2].

The whole collection comprehends 150 specimens exhibited and more than 800 fragmentary pieces stored in the Museum's warehouses: their dimensions range from 6 to $25 \mathrm{~cm}$ of height, with some exceptions reaching $30 \mathrm{~cm}$.

The terracottas, of local production, presents small variations and deformations, due at the pressure exerted for the raw extraction, or different previous drying processes cooking, either by reduction from a matrix or for intentional variations, such as the compression or rework of some details. 
Sometimes, it is also possible to see a hole above the forehead, useful for hanging or supporting the mask, or for the insertion of wires that allow a frontal view. The color, when preserved, is placed before cooking: on the smaller pieces, it is attested, especially in the hair; then, on the bigger ones, it connotes the surfaces.

Conventionally, the identification of the characters represented by masks was based on the description provided by Julius Pollux's Onomasticon [3] (II century AD), author of a sort of encyclopedic lexicon that came to us through a shortened draft dating back, most likely, to the beginning of the III century. The catalog included about 44 different types for comedy, to which Bernabò Brea added other types for tragedy and Satyr plays [4,5].

However, this theory has been more recently overcome by the studies carried out by Schwarzmaier [6] and Mastelloni [2]. According to the latter, the collection of masks can be dated between the first middle and the end of IV cent. BC: a terminus ante quem can be hypothesized with the attack on the island by part of the Syracusan Agathocles in 304 BC. For this reason, the possibility of reading the masks based on models of the new comedy of Menander, who died in 292 BC and whose fortune as a playwright can be placed in the following years, is not sustainable.

The new typological seriation is based on two main groupings, which differs in terms of dimensions, craft techniques, and chronology and formal characteristics: the first group comprehends a series of a few small masks, perhaps produced by a single workshop, from the half middle of IV cent; the second one counts numerous masks varying in size from about $10 \mathrm{~cm}$ to approx. $30 \mathrm{~cm}$, characterized by a more evolved, complex, and varied formal conception and by a lively chromatism. This group can be further subdivided into at least three large subgroups.

The difficulty of establishing typological criteria and applying them, therefore, clearly depends on the craft techniques by which these masks were made (for example, the same matrix can produce different types if used for a man and a woman, while masks that show the same subject but were made with completely different matrices-see Figure $1 \mathrm{a}, \mathrm{c}, \mathrm{d}, \mathrm{f})$.

The function of these theatrical terracottas is a much-debated issue in the literature, given their uniqueness by genre, number, and conservation status, which have no direct parallels in Athens and even in Greece, in general: the different hypothesis leads them back to ludic or representative aspects (belonging to the community of Lipára and the Greek late Sicilian literary and artistic culture), others to the theatrical aspects and Dionysian cult, goddess as well as theater, of vegetation and transformation.

To make this large collection more appealing and accessible to the public, a large number of masks have been brought to the attention of scholars and other professionals by the Museum. A first 3D reconstruction of some masks deriving from digital photogrammetry methodology has been performed by Marraffa [7] in 2017.

By following this trend, our work was carried out using portable equipment and a combination of a high-performance 3D laser scanning system for surveying [8] and a non-invasive spectroscopic approach for the identification of pigments contained in colored mask.

The importance of these reconstructions is given by the increasing number of publications concerning 3D documentation and reconstruction in recent years [9]: with 3D documented data, it is possible to create digital reconstructions and 3D print replicates of archaeological objects, making, consequently, a cultural heritage more accessible for the public. On the other hand, the characterization of materials [10,11], here performed, do not require preparation of samples and it can be essential to deepen our knowledge about materials of which the masks are made or geographic area of provenience [12].

In the current study, we focus on processing measurements acquired using laser scanning during structural testing of 12 clay masks, including three fragmented pieces (see Figure 1) and Raman spectroscopy for pigment identification. Raman technique is inserted into global analytical strategies (such as the study of pigments and minerals) for its capability of materials' characterization in a non-destructive way. The characterization of pigments, binding media, etc., or, generally, the question of 'color' is a large field of investigation in which Raman spectroscopy is regularly used [13]. 
The work also includes the 3D modeling of two calyx kraters and the projection on the plane of the decorative apparatus depicted on their body:

- The first vessel (i.n. 340bis), attributed to the Painter of Maron, active around 340 BC, represents an episode of the myth of Hippolytus;

- $\quad$ The second vessel (i.n. 10,648) is attributed to the painter of Adrastus (perhaps active in Lipára).

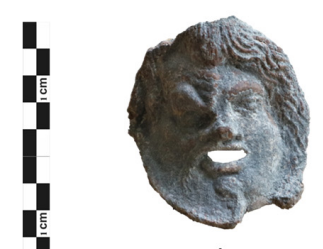

a)

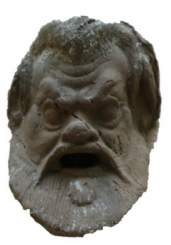

d)

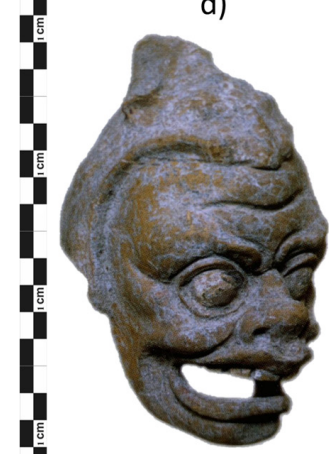

g)

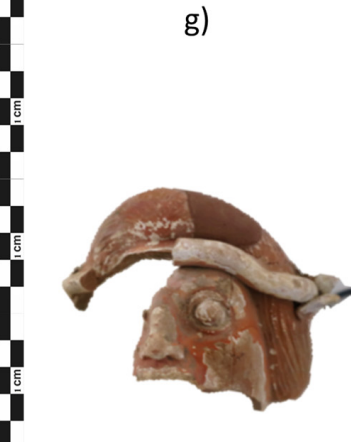

I)

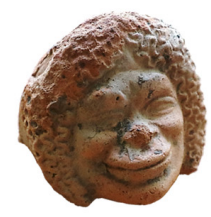

b)

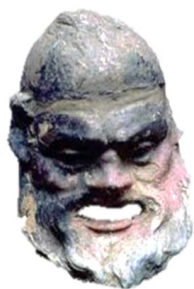

e)

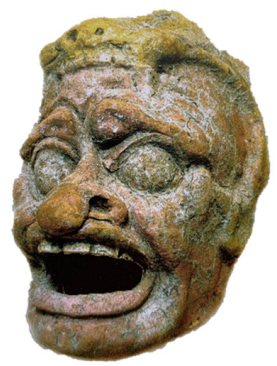

h)

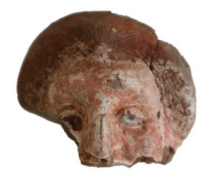

m)

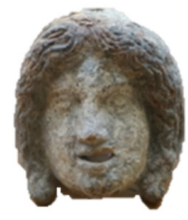

c)

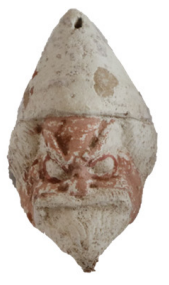

f)

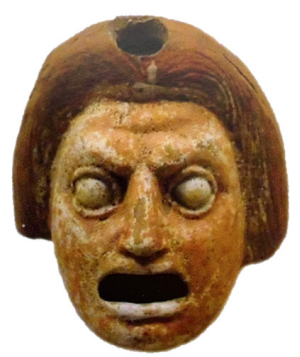

i)

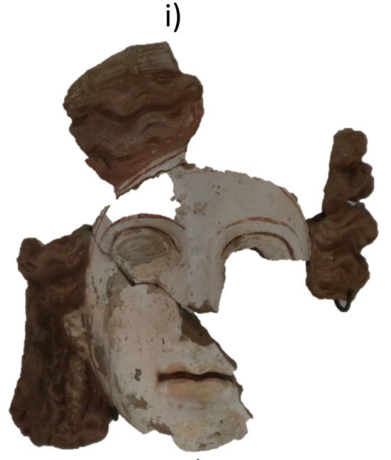

n)

Figure 1. The clay masks analyzed: (a) i.n. 11,114-E (h. $7.8 \mathrm{~cm}) ;($ b) i.n. 10,827 (h. $6.9 \mathrm{~cm}) ;$ (c) 11,114-b (h. 7.2 cm); (d) i.n. 9729 (h. 7.9 cm); (e) i.n. 9219 (h. 11.5 cm); (f) i.n. 13,558 (h. $11 \mathrm{~cm})$; (g) i.n. 14,585 (h. $16 \mathrm{~cm}$ ); (h) i.n. 14,584 (h. $13 \mathrm{~cm}$ ); (i) i.n. 6766 b (h. $13 \mathrm{~cm}$ ); (l) i.n. 11,248 (h. $9.5 \mathrm{~cm})$; (m) i.n. 3375 (h. $6.3 \mathrm{~cm}$ ); (n) i.n. 9768 (h. $16.5 \mathrm{~cm})$.

\section{Materials and Methods}

\subsection{Point-Based 3D Survey and Data Processing}

The surveys of masks and craters have been performed using "Quantum ${ }^{\mathrm{TM}}$ FaroArm", manufactured by FARO - Europe GmbH \& Co. KG (Figure 2), a portable high-accuracy coordinate measuring machine (PCMM) that meets the most rigorous ISO 10360-12:2016 measurements standards: 
the instrument is the fastest, lightest, hand-held, non-contact scanning system available. It is equipped with an interchangeable probe that deploys a blue laser technology (Faroblu ${ }^{\mathrm{TM}}$ laser line probe HD) able to capture in real time a high-density point clouds at over 600,000 points per second reconstructing the surface of objects and features.

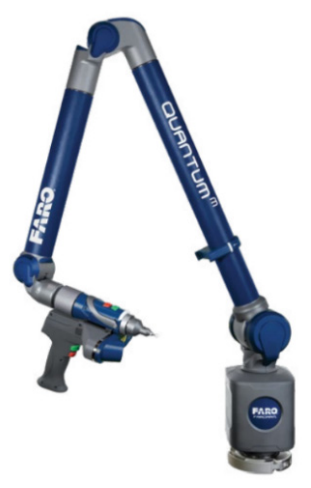

Figure 2. FaroArm Laser.

This technology ensures consistent and reliable measurement, thanks to the shorter wavelength (compared to the red one) of laser, and delivers higher resolution scanning of small element and features (see performance specification on Table 1). The device uses a laser source, which, through a suitable optic, produces a coherent and monochromatic light blade detected by two CCDs (Charge-Coupled Device) and subsequently processed through a triangulation process.

Table 1. Laser Line Probe Specification.

\begin{tabular}{cc}
\hline Accuracy: & $\pm 25 \mu \mathrm{m}( \pm 0.001 \mathrm{in})$ \\
Repeatability: & $25 \mu \mathrm{m}, 2 \sigma(0.001 \mathrm{in})$ \\
Stand-off: & $115 \mathrm{~mm}(4.5 \mathrm{in})$ \\
Depth of field: & $115 \mathrm{~mm}(4.5 \mathrm{in})$ \\
Effective scan width: & Near field $80 \mathrm{~mm}(3.1 \mathrm{in}) ;$ \\
Points per line: & Far-field $150 \mathrm{~mm}(5.9 \mathrm{in})$ \\
Minimum point spacing: & 2000 points/line \\
Scan rate: & $40 \mu \mathrm{m},(0.0016 \mathrm{in})$ \\
& 300 frames/second, 300 fps $\times 2000$ \\
Laser: & points/line $=600,000 \mathrm{points} / \mathrm{sec}$ \\
Weight: & Class $2 \mathrm{M}$ \\
\end{tabular}

Data acquisition is based on the principle of laser stripe triangulation: a laser diode and stripe generator are used to project a laser line onto the object, which is kept still during the scanning process (Figures 3 and 4). The line is viewed at an angle by cameras so that height variations in the object can be seen as changes in the shape of the line. The resulting captured image of the stripe is a profile containing the shape of the object (Figure 5). The position of each recorded point is accurately measured relatively to a known coordinate system. The survey process has been operated using "GeoMagic Wrap" software, which allows to define and modify several acquisition parameters.

The acquired data relative to each sample has been processed using "Geomagic Studio" software through the following step:

- Visual inspection of dense cloud and mesh surface, spikes removal, and small holes filling;

- $\quad$ Alignment of meshes (the Faro aligns roughly the individual scans during the scan processing, so a second alignment was performed);

- $\quad$ Merging of the aligned meshes and generation of the final mesh removing redundant data;

- Slight smoothing (the lowest possible allowed by the processing software) between the merged mesh. 


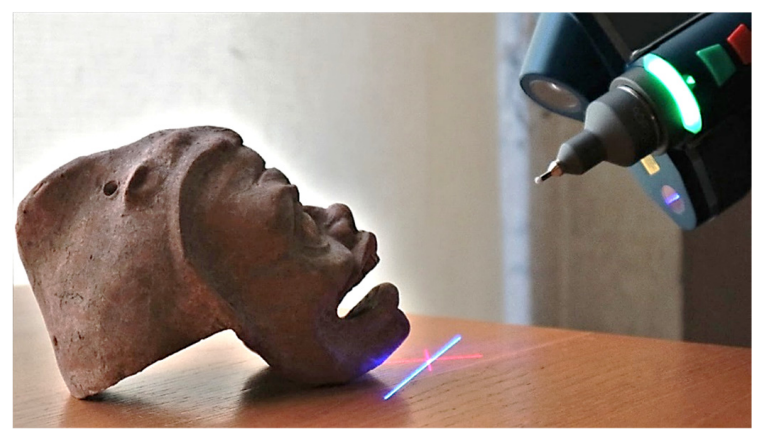

Figure 3. Acquisition stage on i.n. 14,585 mask with Laser Arm.

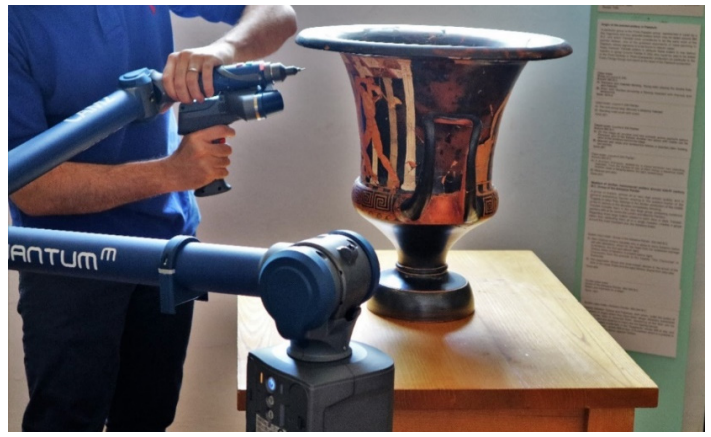

Figure 4. Laser Arm acquisition on Adrasto Painter's crater (i.n. 10,648).

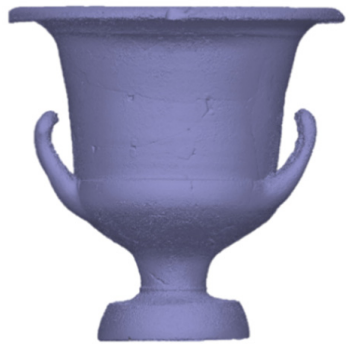

Figure 5. 3D mesh of s.c. Maron krater.

The final model was saved in STL format (Standard Triangulation Language) and used for further analysis.

\subsection{Image-Based 3D Survey and Data Processing}

Also, a scaled structure from motion model of two figured calyx kraters was created using a Canon Eos 7D Reflex Camera to integrate a photographic texture (not acquired by the laser arm) to models (Figures 6 and 7a). In particular, the vases were entirely photo-scanned following a 'converging axes' schema, taking care to get overlap and side-lap between the frames ranging from $60 \%$ to $70 \%$.

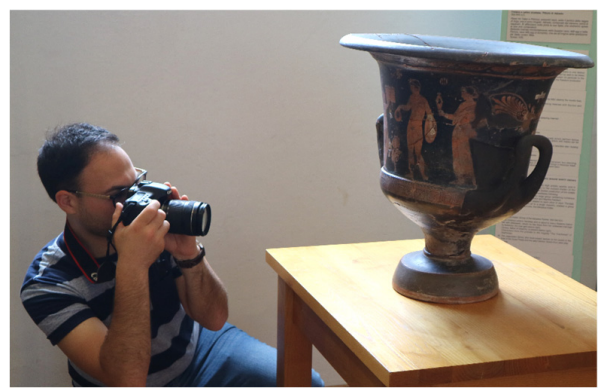

Figure 6. Photo-scansion of s.c. Maron Crater with a Canon Eos 7D camera. 

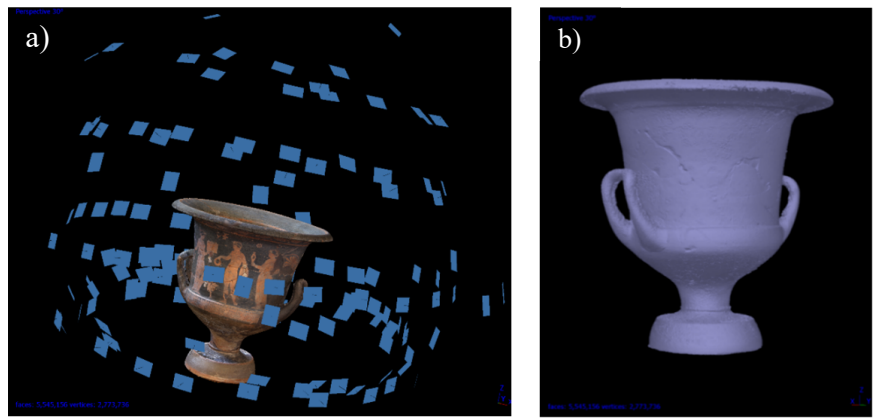

Figure 7. (a) Position of cameras around the vases; (b) 3D meshed model obtained from Photoscan processing.

The photo-scansions of craters have been processed through "Agisoft Photoscan" [14] by following these steps:

- Correction of optical distortion of cameras (by "Lens" plug-in) [15];

- $\quad$ Alignment of the frames by tie points between adjacent frames;

- $\quad$ The building of dense cloud;

- $\quad$ Generation of 3D polygonal mesh (Figure 7b-it is possible to see some small cracks);

- Generation of texture;

- $\quad$ Exporting of results.

Finally, a cylindrical projection of the decorative apparatus of craters was also performed.

\subsection{Raman Spectroscopy Measurements}

A Handheld Raman Spectrometer (BRAVO - Bruker), manufactured by Duo LASER, was used to collect Raman spectra (Figure 8) of the masks in situ. The instrument uses patented technology (SSE ${ }^{\mathrm{TM}}$, Sequentially Shifted Excitation, patent number US8570507B1) [16] to mitigate fluorescence phenomena, and it is equipped with two excitation lasers having wavelengths (DuoLaser ${ }^{\mathrm{TM}}$ ) centered at 785 and $853 \mathrm{~nm}$ [17]. Lasers work together to mitigate the fluorescence, and it is not possible to separate them using the experimental setup.

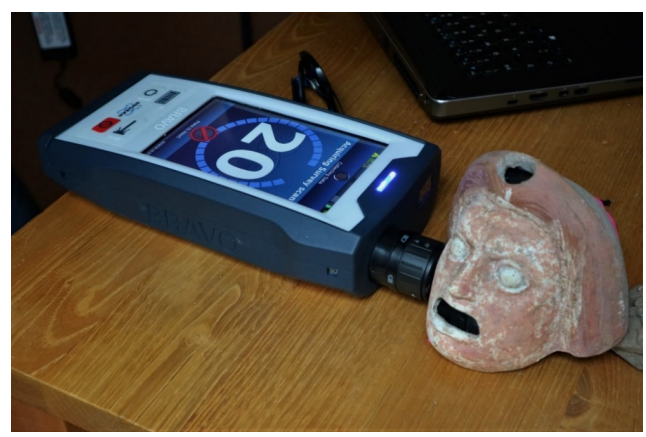

Figure 8. Acquiring Raman spectrum with BRAVO on i.n. 6766 mask.

The spectra were collected in the 400-3000 $\mathrm{cm}^{-1}$ range with integration times no longer than $60 \mathrm{~s}$. In the results and discussion section, we report the only significant result of some clay masks, and we assign the stretching mode of ancient pigments principally based on iron oxide.

The Raman spectra were performed on clay masks $\mathrm{N}^{\circ} 11,248,9729$, and 6766 on the colored part. In mask $\mathrm{N}^{\circ} 11,248$, we analyzed three different points: near the eye and in the hair. We analyzed pink pigment in the cheek on $\mathrm{N}^{\circ} 9729$ clay mask; instead, on $\mathrm{N}^{\circ} 6766$, the analysis was focused on cheek and hair. The results obtained for each mask are very similar to each other. For this reason, we report only one spectrum acquired in every case of study. 


\subsection{Digital Integration}

Some tests of digital integration through operations of duplication translation and the mirroring of the original starting mesh were performed, also using "Geomagic Studio", on fragments presenting gaps on the vertical axis. A roto-transaction allowed, finally, adapting and anchoring the mirrored copy to the original fragment. To best fit the junction between the original fragment and the mirrored copy, the latter was converted from polygon mesh into point clouds. The excess parts overlapping the original finding were then deleted, and a new wrapping operation was recalculated.

It was decided, finally, to trace a separation groove to better differentiate the original fragment from the reconstructed parts, thus, declaring the reintegration action of the gap. Slight operations of 'Smoothing and loosening of the tips', using Geomagic Studio, have made even more evident the readability of the reconstructed parts.

\section{Results and Discussion}

The elaborations of the data allowed to obtain three-dimensional models, metrically correct at very high resolution (Figure 9). Below are displayed the results of the processing stage, from which it is possible to have an idea on the accuracy in the reconstruction of the forms that the instrumental resolution allows.

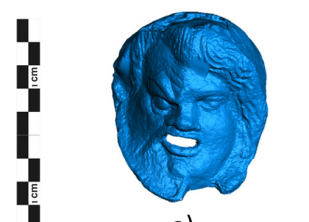

a)

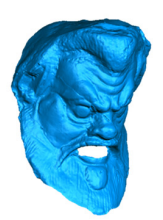

d)

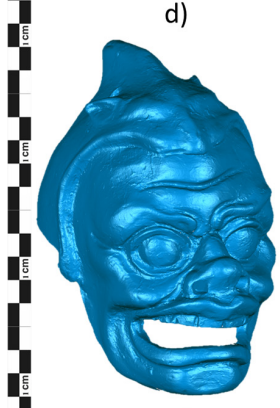

g)

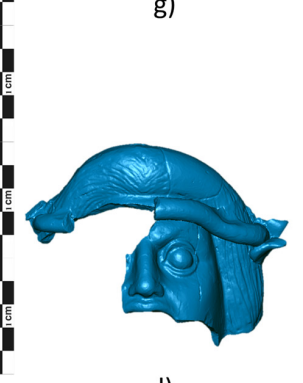

I)

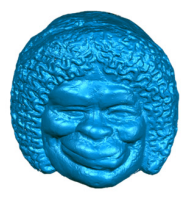

b)

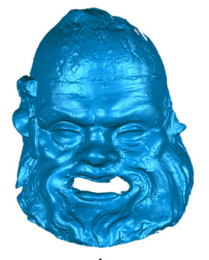

e)

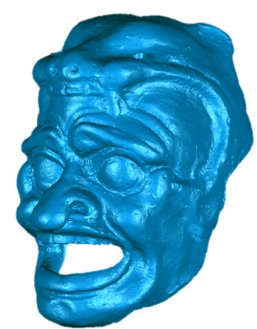

h)

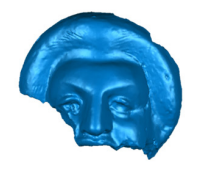

m)

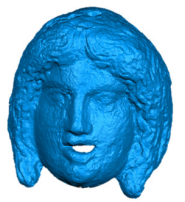

c)
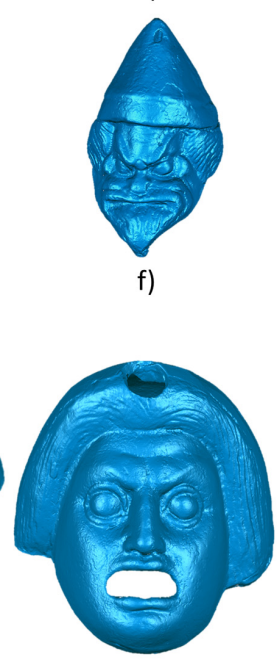

i)

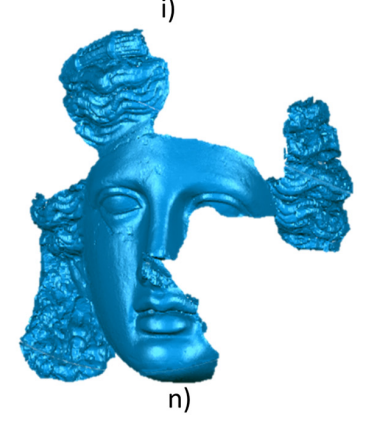

Figure 9. 3D models of masks: (a) i.n. 11,114-E (h. $7.8 \mathrm{~cm})$; (b) i.n. 10,827 (h. $6.9 \mathrm{~cm})$; (c) 11,114-b (h. 7.2 cm); (d) i.n. 9729 (h. 7.9 cm); (e) i.n. 9219 (h. 11.5 cm); (f) i.n. 13,558 (h. $11 \mathrm{~cm}$ ); (g) i.n. 14,585 (h. $16 \mathrm{~cm}$ ); (h) i.n. 14,584 (h. $13 \mathrm{~cm}$ ); (i) i.n. 6766 b (h. $13 \mathrm{~cm}$ ); (l) i.n. 11,248 (h. $9.5 \mathrm{~cm})$; (m) i.n. 3375 (h. $6.3 \mathrm{~cm}$ ); (n) i.n. 9768 (h. $16.5 \mathrm{~cm})$. 
Moreover, we propose below (Figures 10 and 11) the results of the elaborations of the two craters:

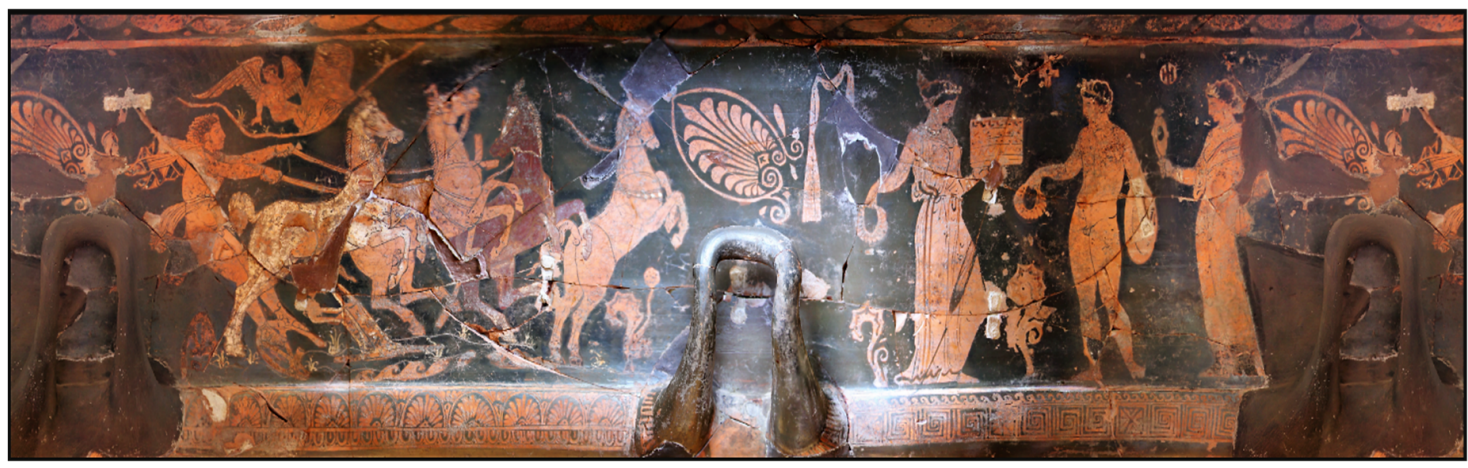

Figure 10. Projection onto a plane of the iconography depicted along the body of the so-called Maron's crater (i.n. 340bis): Hyppolytus and chariot horses.

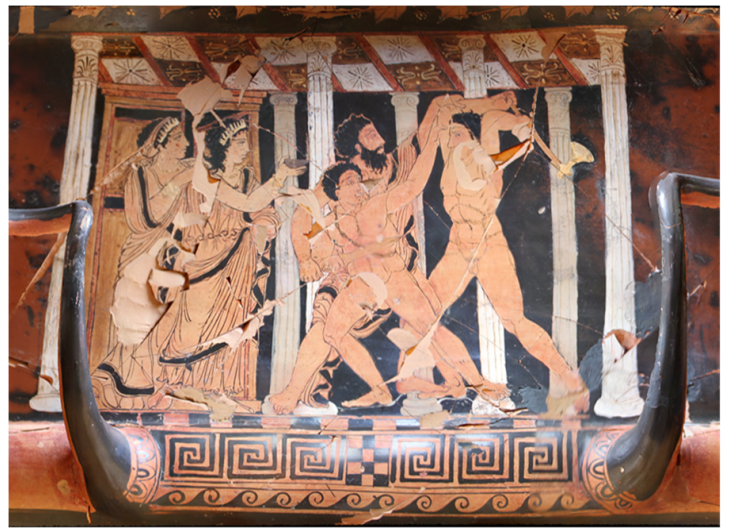

a)

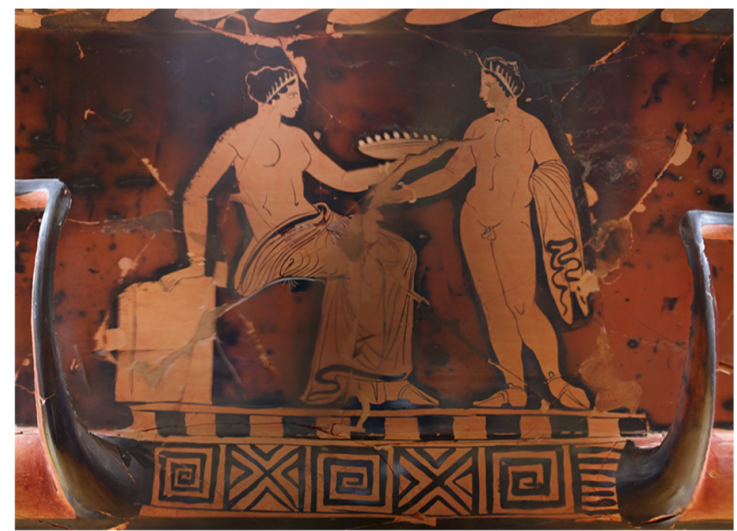

b)

Figure 11. Projection onto a plane of the iconography depicted along the body of Adrasto Painter Crater (i.n. 10,648): (a) Adrastus settles the dispute between Polynices and Tydeus; (b) a female diademata figure offers a large phiale to a young.

The so called Maron crater (inv. 340bis - Figure 6) presents, along the external wall, two different depictions separated by a vegetable element, representing scenes taken from the myth of Hippolytus. $\mathrm{He}$, rejecting the amorous advances of Phaedra, incurs the vengeance of Aphrodite who scares the horses, making them bolt. The chariot is depicted at high speed and lost control, while it is breaking the wheels and the axle of the wagon. Freed from the reigns, the horses' bolt, fleeing in all directions. The depth of field and perspective of the work are suggestive of a masterpiece painting.

The crater by the Painter of Adrastus (inv. 10,648) is organized in two figurative different sizes panels: in the first Adrastus, king of Argos, settles the dispute between Polynices of Thebes and Tydeus of Calydon whose argument was the source of the story of the Seven against Thebes (Figure 11a); the second shows a female figure wearing a diadem and sitting on an altar or sarcophagus, which offers a large phiale to a young with mantle on the left arm. (Figure 11b).

Although the laser-scanner is the most accurate methodology in defining the geometry of objects (and the only one suitable for all those activities, which require maximum precision as digital restoration), it is very poor in photorealistic rendering in relation to the high cost of equipment and elaboration software, which require long processing times and high modeling skills.

Another element of discussion is on a technical nature and depends on the management of high poly digital models, i.e., the meshes characterized by a high number of vertices and faces. The acquisition of data allowed to obtain very detailed and complex models, but its management through traditional 3D modeling and 3D editing software was very complicated, and the integration 
of the missing parts determined an important leap in scale, especially in terms of detail. A strong qualitative and quantitative gap was created between the original fragment (high poly model) and its integration (low poly model).

These irregularities have been solved almost completely by the Geomagic Studio software, through operations of loosening the tips, new phases of wrapping, closing the holes, mesh doctoring, etc. On the other hand, thanks to the structure from motion algorithm, the technique of photo-scanning allows to partially automate the processes once the acquisition scheme is accurately designed, using low cost and user-friendly tools: despite a less geometrical accuracy, this method can offer a more effective photorealistic rendering. The two methods are, however, absolutely complementary to finally get an 'integrated model', which is also proved in our study case.

In the case of craters, in fact, the combined use of both techniques offers an efficient and precise way for executing drawings of painted vases, thanks to stylistic analysis from which it is possible to identify, in some cases, painters and workshops: only a meticulous fine documentation of details may reveal the particularities and characteristics of a painter and can help to recognize these on other vessels. Furthermore, using 3D documentation, measurements can easily be taken even after the recovery of items.

As described in the introductive section, Raman analysis was performed in colored clay masks to identify the pigmentations. The attention was especially focused on few interesting artworks suggested by the Director of Museum.

Figure 12 shows the figures and the respective Raman spectra obtained in red masks $\mathrm{N}^{\circ} 9729$ representing "Lenone" and masks $\mathrm{N}^{\circ} 11,248$ and $\mathrm{N}^{\circ} 6766$ representing two different types of "Giovane dalla chioma ondulata".
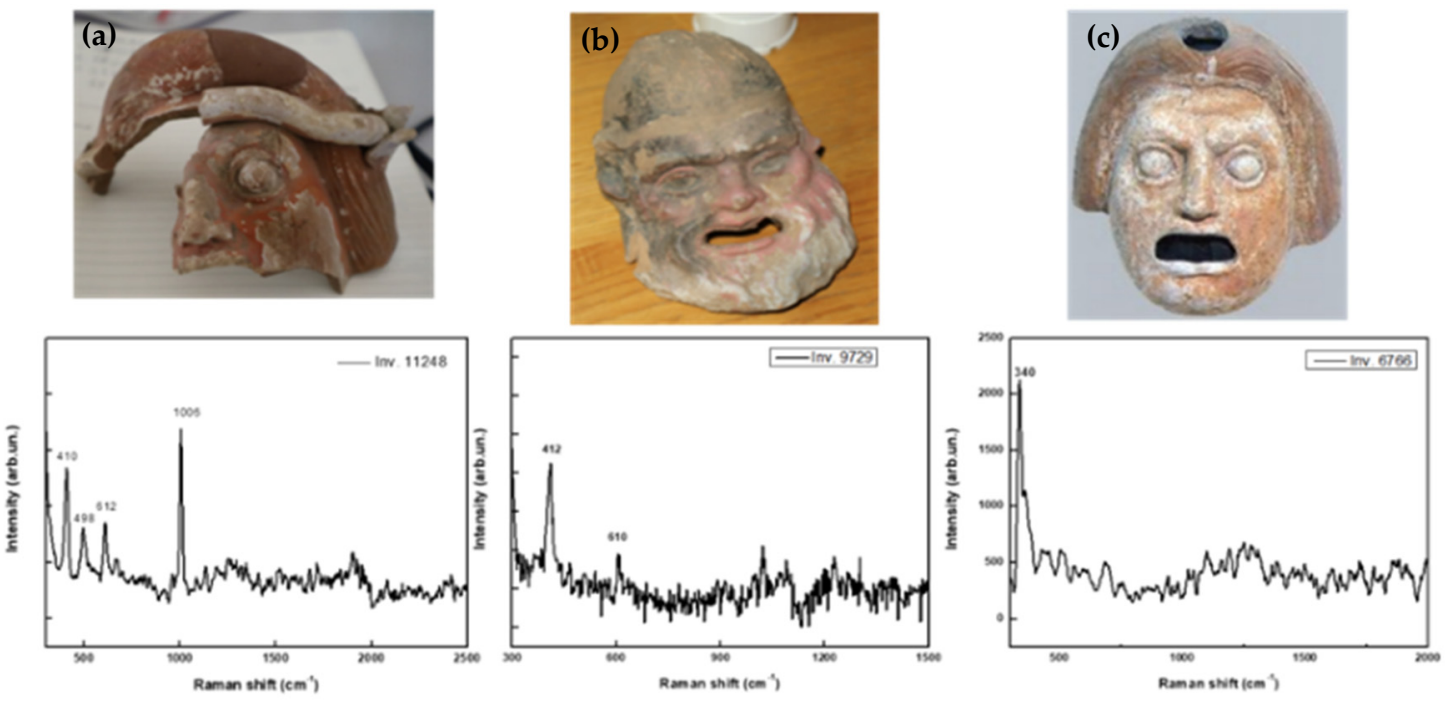

Figure 12. Clay masks analyzed with BRAVO Handheld Raman Spectrometer: (a) clay mask $\mathrm{N}^{\circ} 11,248$; (b) clay mask $\mathrm{N}^{\circ} 9729 ;$ (c) clay mask $\mathrm{N}^{\circ} 6766$.

In clay mask number 11248 (Figure 12a), the spectrum presents bands at 410, 498, and $610 \mathrm{~cm}^{-1}$ attributable to hematite pigment $\left(\mathrm{Fe}_{2} \mathrm{O}_{3}\right)$ and a band at $1008 \mathrm{~cm}^{-1}$ imputable to gypsum $\left(\mathrm{CaSO}_{4} \cdot 2\left(\mathrm{H}_{2} \mathrm{O}\right)\right)$ per literature data [18]. The spectrum acquired on 9729 clay mask (Figure 12b) shows bands at 412 and $610 \mathrm{~cm}^{-1}$ attributable, also in this case, to hematite pigment. Finally, clay mask $\mathrm{N}^{\circ} 6766$ (Figure 12c) shows only one band centered at $340 \mathrm{~cm}^{-1}$ imputable to cinnabar pigment (HgS). Cinnabar is a brilliant scarlet mercury (II) sulfide (HgS) employed since antiquity in very important paintings and art objects. This last result is very significant because it represents a unique case in which cinnabar has been identified on a clay mask in the Mediterranean area. The previously important result of the study in Lipari Museum collection is the identification of cinnabar in the color palette of both Lipari Painter and his followers. This suggests an identical use of materials and a local production [19]. 


\section{Conclusions}

In our study, we focused the attention on processing measurements acquired using laser scanning during structural testing of 12 clay masks and two calyx kraters preserved at the Regional Museum of Lipari “L. Bernabò Brea”.

All these non-contact methods allowed to obtain both 3D models and a precise characterization of the materials (thanks to the Raman analysis) of all the findings listed above, useful for various scopes, such as research, preservation, monitoring of conservation status, testing restoration activities (without intervening directly on the object), promotion, interactive fruition of unexposed pieces, and accessibility. Those methods are frequently used in the Cultural Heritage field: using 3D documented data, it is also possible to create digital reconstructions or 3D print replicates of archaeological objects, and, consequently, museum collections can become more accessible for the public [20].

Author Contributions: Formal analysis, V.M.N.; Methodology, D.G., F.G., and O.A.; Project administration, R.C.P.; Resources, M.A.M.; Software, O.A.; Supervision, M.A.M.; Visualization, G.T.; Writing-original draft, D.G. and V.M.N.; Writing-review and editing, R.C.P.

Funding: This research received no external funding.

Acknowledgments: This work is part of the project "Scienza e tecnologia per il recupero e la fruizione di beni di interesse culturale —"STBIC" - FSE Sicilia 2014/2020 (Programma Operativo del Fondo Sociale Europeo).

Conflicts of Interest: The authors declare no conflict of interest.

\section{References}

1. Mastelloni, M.A. (Ed.) Lipára ed Il Teatro in Età Tardoclassica ed Ellenistica; Palermo, Italy, 2015; ISBN 9788861643444.

2. Mastelloni, M.A. Le maschere fittili di Lipari: nuove riflessioni sulle espressioni artigianali liparesi di IV e III sec. a.C. In Dialoghi sull'Archeologia della Magna Grecia e del Mediterraneo; Pandemos Editore: Paestum, Italy, 2018; pp. 709-720.

3. Bearzot, C.; Landucci, F.; Zecchini, G. L'Onomasticòn di Giulio Polluce: Tra Lessicografia e Antiquaria; Vita e Pensiero: Vicenza, Italy, 2007.

4. Bernabó, B.L.; Cavalier, M. Maschere E Personaggi del Teatro Greco Nelle Terracotte Liparesi; L'Erma di Bretschneider: Rome, Italy, 2001.

5. Bernabò, B.L. Menandro e il Teatro Greco Nelle Terrecotte Liparesi; SAGEP: Genoa, Italy, 1981; p. 7.

6. Schwarzmaier, A. Die Masken aus der Nekropole von Lipari, Palilia 21; Reichert Verlag: Wiesbaden, Germany, 2011; p. 280. ISBN 9783895007101.

7. Marraffa, A. La Cultura Materiale del Mediterraneo Studio e Analisi Delle Maschere Liparote di Argomento Teatrale Della Coroplastica Magno-Greca per la Compilazione di un Protocollo (digitale) e di Integrazione Dati. Ph.D. Thesis, Università Mediterranea di Reggio Calabria, Reggio Calabria, Italy, 2017.

8. Historic England. 3D Laser Scanning for Heritage: Advice and Guidance on the Use of Laser Scanner in Archaeology and Architecture; English Heritage Publishing: Swindon, UK, 2018.

9. Hassani, F. Documentation of Cultural Heritage techniques, potentials and constraints. ISPRS Arch. 2015, XL-5, 207-214. [CrossRef]

10. Vandenabeele, P.; Donais, M.K. Mobile spectroscopic instrumentation in archaeometry research. Appl. Spectrosc. 2016, 70, 27-41. [CrossRef] [PubMed]

11. Vandenabeele, P.; Edwards, H.G.M.; Jehlička, J. The role of mobile instrumentation in novel applications of Raman spectroscopy: Archaeometry, geosciences, and forensics. Chem. Soc. Rev. 2014, 43, 2628-2649. [CrossRef] [PubMed]

12. Mastelloni, M.A. Il gruppo del pittore di Lipari e la pittura policroma vascolare tra IV e primi decenni del III sec. a.C. In Dialoghi sull'Archeologia della Magna Grecia e del Mediterraneo; Pandemos Editore: Paestum, Italy, 2018.

13. Bellot-Gurlet, L.; Pages, C.S.; Coupry, C. Raman Spectroscopy in Art and Archaeology. J. Raman Spectr. 2006, 37, 962-965. [CrossRef] 
14. Agisoft PhotoScan Is an Image-Based 3D Modeling Software that Creates Professional-Quality Three-Dimensional Content from Images. Based on the Latest Multi-View 3D Reconstruction Technology, It Operates with Arbitrary Images and Is Efficient in Controlled and Uncontrolled Conditions. Available online: https://www.agisoft.com/pdf/metashape-pro_1_5_en.pdf (accessed on 10 June 2019).

15. Agisoft Lens Is a Lens Calibration Software, which Estimates the Following Camera Calibration Parameters: Fx, Fy-Focal Length; Cx, Cy-Coordinates Main Point; K1, K2, K3, P1, P2-Radial Distortion Coefficients, Using Brown's Distortion Model. The Estimated Calibration Parameters Can be Saved in a Readable File Format for Later Use in the Photoscan Software. Available online: http://downloads.agisoft.ru/lens/doc/en/lens.pdf (accessed on 10 June 2019).

16. Conti, C.; Botteon, A.; Bertasa, M.; Colombo, C.; Realinia, M.; Sali, D. Portable Sequentially Shifted Excitation Raman spectroscopy as an innovative tool for in situ chemical interrogation of painted surfaces. Analyst 2016, 141, 4599-4607. [CrossRef] [PubMed]

17. Pozzi, F.; Basso, E.; Rizzo, A.; Cesaratto, A.; Tague, T.J. Evaluation and optimization of the potential of a handheld Raman spectrometer: in situ, noninvasive materials characterization in artworks. J. Raman Spectr. 2019, 50, 861-872. [CrossRef]

18. Burgio, L.; Clark, R.H. Library of FT-Raman spectra of pigments, minerals, pigment media and varnishes, and supplement to existing library of Raman spectra of pigments with visible excitation. Spectrochim. Acta A 2001, 57, 1491-1521. [CrossRef]

19. Barone, G.; Di Bella, M.; Mastelloni, M.A.; Mazzoleni, P.; Quartieri, S.; Raneri, S.; Sabatino, G. Pigments characterization of polychrome vases production at Lipára: New insights by noninvasive spectroscopic methods. X-ray Spectrom. 2017, 47, 1-12. [CrossRef]

20. Barrile, V.; Fotia, A.; Ponterio, R.; Mollica Nardo, V.; Giuffrida, D.; Mastelloni, M.A. A combined study of art works preserved in the Archaeological Museums: 3d survey, spectroscopic approach and augmented reality. Int. Arch. Photogramm. Remote Sens. Spatial Inf. Sci. 2019, XLII-2/W11, 201-207. [CrossRef]

(C) 2019 by the authors. Licensee MDPI, Basel, Switzerland. This article is an open access article distributed under the terms and conditions of the Creative Commons Attribution (CC BY) license (http://creativecommons.org/licenses/by/4.0/). 